\title{
To Think About Deliberative Democracy
}

\author{
Tatyana Vasileva Petkova \\ ORCID: 00oo-00o3-4567-8635 • ResearcherID: I-2809-2015 \\ South-West University "Neofit Rilski”, Faculty of Philosophy, Blagoevgrad \\ Received 7 October $2017 \cdot$ Revised 25 November $2017 \cdot$ Accepted 4 December 2017
}

\begin{abstract}
The conflict between digital and real democracy - for thirty years now the digital-virtual public space is the undeniable and the influential factor which influences the human behavior and thinking. The digital democracy is part of this digital-virtual space. This form of direct democracy has got itself the different dimensions: on the one hand, the representatives of a direct and a representative democracy are seek to influence through the electronic media and the digital channels of the representative and the direct democracy, which are a different, as well as the actual policy instruments to try to implement specific applications of the digital media in a politics and for the government activities; on the other hand, the digital democracy has got twenty years of experience in the implementation of a digital democracy in the provision of information, of the online discussions and of making decisions; furthermore, the digital-electronic democracy participates in the real politics. The digital democracy is being considered by the governments and the way to their orientation to the modern and the digital active of the civil society. The digital democracy is a kind of the regulator form of the real social democracy - e.g. the issue of media freedom.
\end{abstract}

Keywords: deliberative democracy, digital-virtual public space, digital democracy, form of the direct democracy.

"Lost is the art of democratic debate. Therefore - we need for more, more, as many debates."

James Fishkin

\section{Introduction}

The words of James Fishkin will have been especially necessary to meet to answer of questions and to confirm the thesis which are being defended with the ideas of deliberative democracy, namely whether deliberative democracy is a bridge namely between and attempt to parry and resolve conflicts that arise between a generalized term the "real democracy" of traditional societies and like general term the "digital democracy" of our modern digital virtualactive societies.

Will we reach a conclusion that deliberative democracy is the linchpin relation with all its possible manifestations? Which could be an answer to these questions: "how could refine the liberal-democracy?" and "how could has legitimized the nascent Internet - virtual civil society?" - in one, together.

If in regard of the liberal-democracy, the deliberalism sounds like positive and

(C) Authors. Terms and conditions of Creative Commons Attribution 4.0 International (CC BY 4.0) apply. Correspondence: Tatyana Vasileva Petkova, South-West University "Neofit Rilski", Faculty of Philosophy, 66 Ivan Michailov st. 2700 Blagoevgrad, Bulgaria. E-mail: tatianavas@abv.bg. 
compelling alternative, then in regard of the virtual civil society. The deliberalism still accepts that it has mostly wishful, even utopianism intentions, which are very definite and easily realizable.

The words about the need for more opportunities for debates of Fishkin (Ackerman \& Fishkin, 2010) - a political scientist at the University of Texas - he decided to examine in social experiment by collecting 343 people in Philadelphia for a weekend of political debate while he is trying to verify that their prescription. The people have been carefully selected to be close to the current perfect representative sample of the US population. The event has received its name and need for such forums, it is called "Congress to discuss national issues". The idea of the organizer is that the debate should not be only preserve territory of the political elites and experts, namely that the true democracy is just that - groups of people can make meaningful choices if they are given enough information to date in a case. Fishkin leads ultimately to another conclusion: such forums give a much more accurate picture of the people's attitudes than the usual survey could do it. And if someone is interested for the public opinion he should conduct such debates, but not just to order poll. Fishkin was called "Don Quixote". He said the idea of even higher lifted up - he offered two weeks before the election to organize "Day for debate". "The Day" will be an official holiday, the registered voting to discuss issues in groups from 15 to 15,500 people.

The ideas for the deliberative democracy we can to find more in the works of the American politician and philosopher John Dewey (1859-1952), in which he calls for rejection of the idea of democracy like a form in which dominates the majority of opinion, without to that opinion to it came after general public discussions between different social groups - majorities, minorities and others (Dewey, 2004).

The American philosopher John Rawls also develops and discusses similar deliberative approach in his book Theory of Justice (1971), in which the author develops a general model for cooperation and negotiation in public affairs, leading to universal consent of the citizens (Rolls, 1998).

Fishkin's idea for "Day for debate" is stunning with its idealism, but has found its proponents. One of them is the law professor of Yale Bruce Ackerman. His argument was the following: "We have to do something dramatic to stop the emptying of American democracy meaningless".

This is an attempt to return to the Greek Agora, or is trying to find new ways to democratic participation of the citizens in making democracy itself?

Perhaps one of the way to really co-participation of citizens in the democratic process in our modern days emerged through the digital democracy, which is very open and receptive and easily suitable for the ideas of deliberalism. The digital-virtual space with its options is like a way to serve for a mediator to parry and resolving a number of the real problems and conflicts arising in and through our real democracy - one that exercised and demonstrated in our politico-social real existence.

On the way here to arise many questions about the words "real", "virtual", "digital" like the author I did not think to go in the explanatory mode etymological definitions of one or another word. The game of the importance and meaning of the words here it is completely unnecessary because the issue is sufficiently clear and relevant.

The fact is that the information technology especially after the emergence and spread of the Internet laid the foundations of some both quantitative and qualitative opportunities for awareness, choice and action to the citizens. Moreover, this digital environment except that it has become in flexible herald of new ideas and sorts of qualitative-quantitative opportunities proved it to be the place that citizens themselves can modify, because in fact, they are these who created it. Along with all, it is not impossible for the citizens that approaching the process of making democracy cannot be changed. The democracy is a process that is not set "here" and "now" in the 
space - democracy is a means to achieve some or other political, social or cultural and economic goals which means that the democratic process is dynamic, flexible and not static.

Under the influence of digital change and making of the democracy, we had to find a flexible approach to projecting a democratic process. Fishkin's ideas of deliberative approach were being proved to be relevant and in tune with the pulse of the time. What are they but looking forward to saving the future of democracy? Whatever they are, if they prove working will be called "deliberative democracy approach" (not of "deliberalise" rather than deliberate - think about, discuss). In fact, Fishkin and Ackerman not offer a new approach and are not innovators of utopian ideals, or who have found a panacea for the smooth democracy just follow the natural course of people's attitudes, recalling worked well social and political approaches for updated at modern conditions of life that could easily be in the sample well-known practical American society. Both agree on the thesis that "Our democracy does work and should therefore be treated and feet". And it is doing us a good job, because it is not just an ideal, but something that answers the basic question: How to live together and how we live together, not a problem, but our mutual benefits?

\section{The deliberative form of democracy}

Democracy in its the most widespread modern version often is characterized like a procedure in which policy decisions are taken in accordance with the will of the majority without therefore need a broad public discussion, since it is assumed that the citizens delegate their representatives of the right to defend and asserted their personal preference - this is the so-called traditional democratic practice.

The difference that brings the deliberative democracy approach is that public decisions could become completely legitimate, if they were put to broad public discussion in which each party has had an opportunity widely and openly defend its arguments to state its position. The model which Fishkin suggests launched the thesis that so the citizens could come to some decisions on social and rational political development, which most closely suiting them for public good. So and the procedure through which have reached to these decisions, will be enough legitimately-democratic so could be pleased with taken decisions - because the procedure is projecting by themselves, i.e. their choice is deliberate (conscientious). Lachezar Antonov (2014: 101-102) wrote:

“The real 'deliberative turn' in the theory of democracy (...) occurs about 1990 (Dryzek, 2000: 2) - under the influence of acquired wide academic response to controversial theory of democracy of Jürgen Habermas and in particular - of the display this theory idea that in solving common problems, individuals must rely on profound debate in which the decisive roll only has the power of a good argument ...."

So if we are afford to use the concept of Jürgen Habermas for the occurred "deliberative twist" after 1990 and it thanks of information technology and the virtual space, complying increasingly again with political theories, we could conclude that: the meaning of the democratic legitimacy consists in the right of free and equal citizens to participate in public debates in which after critically study of the based of arguments, to take collective political decisions which to determine Joint future life of the citizens in the political and social space. So the deliberative turn would have its terms of the publicity - there will be a public deliberation openness, publicity - anyone who believes that the debate not care could be included in it. This thesis defended James Bohman (2000: 16): "inclusion of everyone who has been affected by the decision, substantial political equality, including equal participation in deliberation, equality in the methods of decision making and agenda setting, free and open exchange of information and the grounds clear enough understanding the issue being discussed and the views of others, etc.".

The "Deliberative turn" as assumed Jürgen Habermas could be activated, if it is 
applied to all communities which are being need of deliberative regulating conditions of their joint life. Provided that these communities can constitute themselves on the basis of deliberation, they would built one flexibly and active civil body (see Habermas, 1998).

\section{Internet like a platform of the deliberative democracy}

To Don Quixote more like that British professor Tim Berners Lee, who invented the World Wide Web, whose nickname is "The man who climbed the world online" and who long thought, how can be saved the democracy and finally he is being given through Internet his recipe of the humanity. For three years he invented version, tested it in his mind and weaknesses, which eliminated in the next version, tested it in his mind and weaknesses, etc. So come to the curartve decision: as by the method of verification and falsification can to be built digital working platform such like the Internet and could be written e.g. the Constitutions of the democratic societies, i.e. to be written by the people rather than their representatives, as platform to the Internet which will be supported by people of over the world. In these constitutions should have all possible safeguards against that the representatives not see themselves like nothing more than servants of his people (see Berners-Lee, 2000).

“The democracy, Sancho, is on top of the spe ...", the constitution. The shortage of democracy is like the shortage of energy resources or a lack of diversification in them. Both, other portend a difficult life. Place where unconditional permanent ongoing debate is cyberspace. There the Forum is permanently open and up. If by the ideas and practice of research positions by the method of Fishkin for formation of deliberative political culture of the people - to debate and listen - before discussions investigate the level of knowledge the positions of representative their sample of participants in the forum, after hearing the discussion of experts make a new study of their positions as general basis conclude it in the digital-virtual environment, this change and update posts and positions is very faster, and could include any number of persons, regardless of their location in space - it is one of the ways of the deliberative democracy to the digital democracy through which a deliberative debate will be able to complicity maximum number of people.

The digital democracy is it fact or just an idea? Near the 25 years the digital-virtual public space is undeniable and influential factor that influences human behavior and thinking. The digital democracy is part of this digital space, which through social networks, electronic media and the entire data volume flowing through them, to form opinions and behavior of the recipient.

In fact, this kind of experience the moment of informational deliberative democracy in much of the world has led to:

- The real democracy in societies;

- In a simply serve like a catalyst for the emergence and experience to change the longestablished regimes and rules - "he Arab sping" or "The Colored revolutions", with all its pros and cons;

- In the third, in which the real socio-political democracy is a fact - serve like a corrective of power - the USA the EU, Central and the South America and etc.

Let's not dwell on the power of the social networks to organize the people and cause them to change the world, though this kind of super-fast mobilizing force of the protest, security or voice, is one of the most vivid confirmation of the germ and existing digital deliberative democracy.

This type of democracy has its different dimensions already been clearly manifest: 
- On the one hand, the direct and representative democracy is being seek to influence by the electronic media and channels of the digital representative and direct democracy, which differ, as well as actual policy instruments to try to implement specific applications of the digital media in the real policy: in government activities and in the functions of various NGOs or international organizations. There are many examples. In cases were appropriateness those which commit the positive political world civil community about the socio-cultural studies: online petitions, online recruiting humanitarian aid donations to organizations such like UNICEF, UNESCO, Greenpeace etc;

- From another hand, the deliberative digital democracy has accumulated more than twenty years of experience in the implementation of the digital democracy in the provision of information, online discussions, debates and decision-making;

- Moreover, the deliberative digital democracy is electronic participation in the real politics - examples for that are: e-government, e-voting and i. e. - that is a kind of legitimization of the deliberative digital democracy like not just of imaginary phenomenon, and its institutional instrumental performance. The deliberative digital democracy is being considered by governments like a way for their forward-modern digitally active civil society. The deliberative digital democracy is a peculiar kind of regulator and is also in conflict with the real democracy for example, the problem of the media freedom. The electronic media are freer than printed - this can easily be verified by being compared electronic editions of the newspapers and the television stations with their electronic competitors that have no real printed paper body or real television channel (Press Freedom Index, 2013).

With application of the personal computers and the Internet on a large scale in on 80th/90-th of 2oth century, the electronic media, although in the form of a time immediately appealed to the imagination of the future observers, scientists and early founders of digital social networks and media. They started with more or less utopian visions of the future in the field of politics and public structuring - of that respect deliberative perspective proved extremely suitable as a platform for the virtual political debate, one that can be projected into the reality.

The following characteristics of the computers like connected to the Internet were like manifestations of revolutionary or at least transformative consequences for the democratization of politics and society as a whole.

The Internet has become in:

- Interactive environment that distract us from unilateral communication of existing media;

- An active and creative environment, allowing users to convert viewers, audiences and readers in participants;

- Direct environment in which individual users are able to determine from a distance, what happens at the center of the political life, along with other information on real politics come mostly from their practical experience and the traditional media and massive media; being adopted;

- Platform where everyone is equal with the others, but must prove himself before

- Network environment allowing collective creation of products online and not primarily by individual authors or business, as in the real market economy - network marketing, network marketing and management of activities of small, medium and large traders. The digital market economy is a kind of meta diversification of commodity markets from whatever nature they may be. The deliberative democracy of network market economy today is undisputed fact and condition for successful business - and we know well that the economic and the politic are inextricably linked; 
- The "Network society" (a term of Manuel Castells) like a stratified structure of decentralization, which is an attempt to change the vertical social hierarchy network society.

Castells (2004: 452) gives the following definition for the networked society:

"The network is a set of interconnected nodes. The hub is a point where a curve intersects itself. If we talk specifically, what constitutes a unit depends on the specific networks in question. These are stock exchanges with their auxiliary centers for advanced services and the system of global financial flows. These are the National Councils of Ministers and Commissioners in the political network of the EU. These are fields of coca and poppy, illegal laboratories, clandestine landing strips, street gangs responsible for laundering money to financial institutions narcotic trafficking; which penetrates the economies, societies and countries around the world. These are television systems, entertainment studios, graphics computing environment, newsrooms and mobile devices generating, sending and receiving signals in the global network of the new media, as the basis of cultural expression and public opinion in the information age".

According to him, the network designs and constitutes a new social morphology of our societies. Mutual overlapping and interlocking of the networks modifies a primary way actions and results in the production, experience, the power and the culture. For Castells namely the "network society" is the basis for the formation of the global modern society and way the dileberative democracy can become accessible thesis in the political space. Thus precisely the network society is the next stage in our social development after the information society - 80th/90-th of 2oth century. He believes that technologies are not sufficient to define modern society. The cultural, economic and political factors related to each other are precisely those which form the network society, they are those who define it. To reach it, it should be prepared from the information with the help of a quick and easy access to information, in any direction, which in all cases life-changing of the societies, which becomes free, easier and synchronized. Castells (2004: 82) wrote:

"In the last quarter of the twentieth century in the world there was a new type of economy that I call informational, global and network with the intent to reveal its main distinguishing features and to emphasize their mutual interplay. It is informative, because hers productives and competitiveness of its units or businesses (whether companies, regions or countries) depend to a basic level of their ability to generate, process and apply efficiently based of the knowledge information. The economy is global, because the key activities of production, consumption and turnover, as well as their components (capital, labor, raw materials, management, information technology markets) are organized on a global scale. It is a network, because in the new historical conditions generate productivity and realization of competition is by and a global network of interaction between the business-networks. This new economy emerged in the last quarter of the twentieth century, for the information technology revolution provides the necessary facilities for its development".

The Information society through the processing and transformation of the information affects all forms of the human activity makes possible the establishment of an indefinite and unlimited number of linkages between different fields and between segments in the different activities. To arise network and the deeply interdependent economic, political, social, cultural and any kind of systems with increasing success administered and applied achievements and progress in technology, knowledge and management for the purpose of the technology, knowledge and management. Jan van Dijk (2006) rather talk and consider the network communities, like a specific form of socialization, sociality and relevant consequences of them. His research is related to the sociology of the information society and the social aspects of the new electronic media. In later his work and his ideas evolve to findings that social inequalities which are inevitable and irresistible in our societies will lead to inequalities and not equal access to digital and electronic media of any kind and type information (see Dijk, 2005). To Van Dijk the "network society" is a structure of social construction that combines social and media networks, and creates a kind of horizontal social structures which "slicing" the basic social structures and the primary mode of 
organization at all levels (community groups, individually). He makes a parallel between this type of new society with mass society which is a secondary structured of the groups, organizations, associations, organized around the physical intimacy. If for Castells networks are those which are the basic element of the modern society, then for Van Dijk these elements are still individuals, groups, organizations and communities which are bound by the network. Yes, the information forms the basis of modern society, it globalizes this society and the virtual support and undermines the limits set in the social structures, but it segment - the networks have split it into different forms of organization and infrastructures to a secondary level. According to Van Dijk, parallel network structures are being received. Some of the benefits of network structure that describe and characterize the network society: the advant ages of network objects, whether they are certain areas of reality or society as a whole is to have the "ability" to evolve towards cost optimization in the form of material resources, effort or public power. The most common form in which it appears that the change in the relative weight and importance of the individual involved in the network of factors. So those "knots" in the network, which in previous stages had key developed a new "role". This feature is essential because it allows the network structure to survive and adapt best to changing conditions. The lack of one obeying the network center its making it not only more adaptable to changing conditions, but much more resistant to adverse changes both inside and in the environment; the network (Web) is fundamentally impossible to manage with a known time of strong nation states and even of the global capitalism methods. So far, the sharp clash of these new structures of network type long known and significantly more convenient to maintain control hierarchical structures yet, but it seems inevitable. Although here and there arise hotbeds of tension, can not yet indicate pronounced winner. There are already indications that the network structure is more vibrant and chances are of its. Argue that it gives the dispute who should rule the Internet. The USA experience to continue to monitor the global network through ICANN (Internet Corporation for Assigned Names and Numbers) comes across more resolute resistance from the European Union and many countries and people from Asia and Africa. Temporary solution to this dispute is discussed at the World Summit on the Information Society of the United Nations in November 2005, for establishing the Forum on Internet Governance (IGF). It was formed in mid-2006 and enable all the important issues on the global network to solve a wide range of stakeholders in a new structure. But in practice still remains an open question how to control and manage a network structure that no single center. The network is the most adequate structure to optimize the synergistic effect of all (similar thesis supports Bob Metcalfe, see Metcalfe, 2000). This structure is more adequate in terms of the economy, new technologies and rapidly changing market conditions than any another structure.

As Van Dyke (2013) writes on the one hand, the effects of digital democracy have often been formulated in terms of total turnover, which means that a dibelerative democratic revolution in politics and government, or technological solution of the main problems of political activity and the confidence of citizens in government, would be helpful. The other that digital democracy also was seen as a tool that only through it will be over and there will be a proper exercise of beneficial social policies and ways of making political decisions. This is because the assumption that the medium such as the Internet is a democratic itself is slightly wrong. Logically, that alone technology can not be a free value, but alone determines directions, structures and management modes, which could contribute to conscious free thinking - i.e. the digital environment to serve as a platform of the deliberative digital democracy.

Over the past 35 years we are being witnessed four waves of these expectations, all of they are being based on the list of characteristics listed here:

In the 80-th years of the 2oth century the prospect "teledemocracy" come to the fore, such as writing Artirtan (1987), Becker (1981) and Barber (1984). The Athens Agora is the most important source of inspiration for the idea that the networks citizens will be able to implement the policy and determine what will happen in the center of society, they observed first of its cable 
television and in Internet connections. The expectation then was still that the removal of the space barriers through the Internet and communication technologies through their central-plant capacity without a specific center will facilitate and allow the formation of forms of direct democracy without intermediaries such like parties and representatives and even lead to irrelevance of the governments;

In the early 90-th years of the 2oth century were being appeared the perspective of the virtual community (Rheingold, 1993). From this perspective, the growth of "Use net" group and other online communities are being supposed to stimulate and general online community by community interests and stimulate existing online communities to support the existing physical communities. The main expectation is that these virtual communities can contribute to the restoration of so called "lost community" in modern society, which means a crisis of the traditional village and neighborhood like a communication, sociability and closeness.

The beginning of the new century was the age of the Internet hysteria after the massive spread of the Internet in society. Here visions of "New Democracy" proved that they are equivalent to the vision of the "new economy" (Shapiro, 2000). The basic idea is the prospect of mass participation in politics and political decision-making though the Internet. In some "visions" those of the futurists - the citizens can even bypass the institutional policy in the country to create their own socio-political decisions and political reality. From the perspective of governments, first experiments were made in online consultations and debates on citizens considered the government's plans. The main expectation is that it will expand the participation of citizens and their desire to be really active factor in the political life and decision even be more active only virtual.

Today, nearly 20 years since the beginning of the new century and after the massive burst of the "Internet bubble", we have seen all sorts of popular Web Perspectives (O'Reilly, 2004). We are seeing a sharp rise in the participation in and use of the Internet by consumers and creative producing and projecting its content. But there is still an expectation that has yet to be usergenerated virtual network, the desire as complicit virtual citizens to contribute more to the development of all sorts of policies: with online petitions, blogs and web sites, social networks, virtual civic journalism, education, etc. Some observers even speak of "state generated by the consumer", i.e. the creation of a "meta rational sense" to be the fruit of infancy and evolving virtual deliberative democratic civil society that constantly update-generated "meta-rational nature" (Leadbeater \& Cottam, 2008; Frisssen, 2008; Paparachissi, 2009).

As we see the true idea of the deliberative digital democracy is very old. This idea is not so much aimed at the digital as such - technology in this case serve as a medium to allow this kind of "meta" or "more" deliberative democracy to be realized. It is an idea that democracy is primarily running like a debate running in a dialogue and that democracy should not be imposed, controlled and it be projected by us humans to be self-sufficient, like the autopilot in an airplane - a computerized machine, which manages the airplane in the most correct way, the pilot would have to intervene in the management of the machine only in a crisis situation and makes no passengers to think about whether the airplane should turn to left or right.

In much the some manner the deliberative digital democracy leading the country to the best possible optimal development without consulting unnecessary cases to the people who have an opinion on this or that issue. That this is a triumph of reason over populism could even say that it is a triumph of reason over experience itself society for democracy. Moreover, this is the triumph of the artificial intelligence on the natural. In many cases these days it is clear that artificial intelligence prevail over the natural mind, which is very psychologically loaded with emotions and that it relies on populism.

The greatest tragedy of our democracies today is that they depend too much of populism and what could help people develop their democracies in a much more populist, freer 
way through the deliberative democracy, as well as its digital form - i.e. abetting the free rational communication, discussion and debate on issues and problems of democratic civil process in cyberspace.

Questions arise: What will be those computers which will manage us and ultimately, who is behind them? This deliberative digital control to what conflicts will result in reality? Will there be a point of conflict in which to meet and clear differences between the digital and the real democracy that still are not fully deliberative basis, could even say that unfortunately, because the deliberation is still very wishful to the democratic process, most so called: "liberal democrative societies"?

Once Winston Churchill said: "It has been said that democracy is the worst form of government except all the others that have been tried". This is true retroactively when Winston Churchill said it in 1947 we did not have computers such as we have now, we have not had technologist possess now, the idea of artificial intelligence thesis was only in fantasy novels. But the days of Winston Churchill has remained his other thought: "The empires of the future are the empires of the mind". That is the fundamental difference from today with what it was yesterday that we have such opportunities that are before our your humanity has never possessed. This is a sign that we need to think about the thousands of opportunities that we will have tomorrow because the most important thing is already done - put are the basics of virtual space.

Moreover, if we use more of ours brain capacity as do dolphins compared to us humans (we use up to $8 \%$ of the capacity of our brain) - for example, the digital deliberative democracy could be one of the pillars that push for greater brain activity. Because behind these computers today stand real people and the democracy that we have in our actual societies for ourselves. We should try to implement freedom of behavior, self-expression that projected in the virtual to apply them in the real space. This will be a way to get back to "the art of democratic debate" (in the words of Fishkin), because we should not forget that the debate is a form of conversation in which leads to some truly, useful standard or reasonable solution. It creates relevant question: whether the deliberative form of digital and real democracy will not undermine the existence of governments, international and non-governmental organizations? The answer is in the positive direction, though still similar response from the perspective of today, it sounds like a utopian idea or futuristic prerequisite.

To them meaningless, but people deliberately created them, these forms of control, because they not have found another way to limit, control and influence over ourselves. By the deliberative form of digital democracy the people could to devote much of progressive idea like: exploration of the space, or explore the ocean bottom - or like a people to learn to think primarily about the real things around us and within us, not politics, and conflicts that give rise to our reality with short-sighted political and economic decisions taken by politicians how govern our countries. Decisions which directly affect over our social life and future. The humanity has very serious questions to resolve, which could devote its intellect, not of who governs us accurate - as for example, when we are flying on an airplane in most cases, do not remember what was the name of the pilot, who was driving our airplane, even through the pilot at the beginning of our flight was being presented us has called: "Have a nice flight!".

So and we need to dream to live in countries where we do not need to know and remember the name of our president or prime minister, in the same way not remember or do not know the name of the pilot of our plane. In mostly we learn and are interested in the name of the pilot of our airplane only when the airplane crashed and then if we are still live. 
4. Conclusions: We need more philosophy in the politics and governance of our societies and countries

There is a specific sphere in philosophy, which is called the Philosophy of Politics, and it has nothing to do with political and political philosophy. The goal of the Philosophy of Politics is to see and analyze such rudiments of our political morality such as: power, governance, democracy, choice, dialogue, debate, and encounter in the spirit of de-liberalism.

Today, virtual space is constantly flooding us with fake news. The false news spreads through social networks, and instead of offering and serving up-to-date information for the needs of a more wise mankind, the fake news is a convenient mechanism for manipulation and conflict, for and as part of the expanding information war. The political parties themselves are publishing news that attempts to "desinform" to blur the opposition and help their own programs and political goals, and they often ask, "who creates a false news, how it spreads and whether it can be stopped?"

An option to emerge from the "lagging labyrinth" of political conflicts turns out to be a deliberative debate through the new types of discourses that are being conducted on a new communication channel - the Internet, which is also a new environment.

\subsection{General conclusions}

This text started with the following keywords: deliberative democracy, digital-virtual public space, digital democracy, form of the direct democracy. In the analysis we tried to think about the deliberative democracy. We tried to observe the conflict between digital and real democracy - for thirty years now the digital-virtual public space is the undeniable and the influential factor which influences the human behavior and thinking. The digital democracy is part of this the digital-virtual space. This form of direct democracy has got itself the different dimensions: on the one hand, the representatives of a direct and a representative democracy are seek to influence through the electronic media and the digital channels of the representative and the direct democracy, which are a different, as well as the actual policy instruments to try to implement the specific applications of the digital media in a politics and for the government activities; on the other hand, the digital democracy has got twenty years of experience in the implementation of a digital democracy in the provision of information, of the online discussions and of to giving decision; furthermore, the digital-electronic democracy participates in the real politics.

As a general conclusion we can conclude that the digital democracy (through deliberative analysis) is being considered by the governments and the way to their orientation to the modern and the digital active of the civil society. The digital democracy is a kind of regulator form of the real social democracy - e.g. the issue of media freedom.

\section{References}

Ackerman, F., \& Ackerman, B. (2010). Why the Lib Dems do well out of TV debates, http://www.theguardian.com/commentisfree/series/general-election-2010-cif-at-the-polls . Accessed 22 November 2017.

Antonov, T. (2014). The development of ICT and new horizons for the deliberative democracy. In: Digital culture and society. "Neofit Rilski" Blagoevgrad Academic Press. 
Arterton, Ch. F. (1987). Teledemocracy: Can technology protect democracy? Newbury Park, CA: Press.

Becker, T. L. (1981). Teledemocracy: bringing power back to the people. Futurist, 15(6), 6-9.

Barber, B.J. (1984). Strong democracy: Participatory politics for a New Age. Berkeley, CA: University of California Press.

Berners-Lee, T. (2000). Weaving the web: The original design and ultimate destiny of the World Wide Web, Press. http://www.amazon.com/Weaving-Web-Original-UltimateDestiny/dp/o06251587X. Accessed 22 November 2017

Bimber, B. (2003). Information and American democracy: Technology in the evolution of political power. Cambridge University Press.

Castells, M. (2004). The rise of the network society. Sofia: "LIK" Press.

Dewey, J. (1994). Democracy and Education Courier Dover Publications, NY,

http://www.google.bg/books?hl=bg\&lr=\&id=19ajcXf4MCYC\&oi=fnd\&pg=PA1\&dq=john+de wey, + democracy\&ots $=$ lHtw4rRjEb\&sig=bBgVn9LyNR1DviNQBeU6B1iWkwA\&redir esc $=\mathrm{y} \#$ $\mathrm{v}=$ onepage\&q=j ohn\%20dewey\%2C\%20democracy\&f=false. Accessed 22 November 2017.

Dijk, V, J. (2005). The deepening divide: Inequality in the information society. SAGE Publications Press.

Dijk, V, J. (2006). The Network Society. University of Twente, Netherlands; SAGE Publications Press.

Dijk, V. J., \& Jan, A.G.M (2013). Digital democracy: Vision and reality of public administration in the information age: Revisited. IOS- Press. http://www.utwente.nl/gw/vandijk/research/itv/itv plaatje/Digital\%20Democracy\%20Vision\%20and\%20Reality.pdf. Accessed 22 November 2017.

Frissen, V. A. J. (2008). The E-mancipation of the citizen and the future of e-government: Reflections on ICT and citizens "participation". A. Anttiroiko Press.

Habermas, J. (2008). Between facts and norms. The MIT Press Cambrige.

Leadbeater, Ch., Cottam, H. (2008). The user-generated state and public services 2.o. http://www.charlesleadbeater.net/archive/public-services-20.aspx. Accessed 22 November 2017.

Metcalfe, B. (2000). Internet collapses and other InfoWorld punditry. IDG Books Press.

Paparachissi, Z. (2009). The virtual Sphere 2.o: The Internet, the public sphere and beyond. In: A. Chadwick \& Ph. Howard Press. http://en.rsf.org/press-freedom-index-2013,1054.html. Accessed 22 November 2017.

Reilly, T. (2005). What Is Web 2. http://www.oreillynet.com/pub/a/oreilly/tim/news/2005/09/30/whatis-web-20.html. Retrieved September 17 2010. Accessed 22 November 2017.

Rols, J. (1998). A theory of justice. Sofia: C. A. Press. 
T. V. Petkova - To Think About Deliberative Democracy

C O A $\mathrm{s}$ 